\title{
Natural variation of bovine milk fat globule size within a herd
}

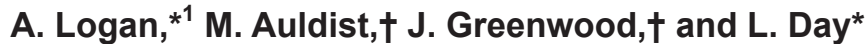 \\ ${ }^{*}$ CSIRO Animal, Food and Health Sciences, Werribee, Victoria, Australia 3030 \\ †Department of Environment and Primary Industries, Ellinbank Centre, Farming Systems Research Division, Ellinbank, Victoria, Australia 3821
}

\begin{abstract}
Native milk fat globule (MFG) size, $\mathrm{pH}$, total fat, protein, and lactose composition in milk from individual cows was examined in autumn and spring 2012 and autumn 2013. Mean MFG diameters ranged between 2.5 and $5.7 \mu \mathrm{m}$. Some cows were observed to consistently produce small or large MFG throughout the sampling period, though trends were not consistent across all cows. Small-MFG milk contained more total polar lipids; however, the relative proportion of individual polar lipids did not differ with MFG size, with the exception of phosphatidylcholine, which was greater in small-MFG milk. No signficant correlation between MFG size and proximate composition, including calculated fat yield or $\mathrm{pH}$, was found. This work revealed a natural cow-to-cow variation in MFG size exists, which could potentially be exploited to improve the functionality of milk for manufacturing and some products.
\end{abstract}

Key words: milk fat globule size, milk functionality, natural cow-to-cow variation

\section{INTRODUCTION}

Milk fat is typically around 3 to $6 \%$ of total milk by weight (Holmes et al., 2003) and exists as spherical lipid globules dispersed within the serum phase. These milk fat globules (MFG) range in size from very small $(<1 \mu \mathrm{m})$ to very large $(>10 \mu \mathrm{m}$; Walstra, 1969; Michalski et al., 2001) and are stabilized by the milk fat globule membrane (MFGM), which is a thin trilayer membrane composed primarily of polar lipids (such as phospholipids and sphingolipids), proteins, and enzymes. The majority of milk phospholipids are associated with the MFGM and account for $1 \%$ of total milk lipid composition. The MFG core accounts for a further $98 \%$ of the total milk lipids and is made up of triacylglycerol of varying chain length FA (Smoczynski et al., 2012). This includes palmitic (16:0), oleic (18:1), stearic (18:0), and myristic (14:0) acid as the most dominant FA, at about $30,23,12$, and $11 \%$ of total

Received February 3, 2014

Accepted March 24, 2014.

${ }^{1}$ Corresponding author: amy.logan@csiro.au composition, respectively (Månsson, 2008). Specific milk fat FA and polar lipids have been associated with beneficial health effects; for example, butyric (4:0) and rumenic acid (cis-9,trans-11 18:2, a conjugated linoleic acid) and sphingomyelin are reported to be anticarcinogenic (Parodi, 2004).

The size of the MFG can affect the functional and nutritional properties of the milk, as well as FA composition (Timmen and Patton, 1988; Michalski et al., 2005; Lopez et al., 2008). Recent studies suggest that benefits exist from using milks with different sized MFG distributions for the manufacture of dairy products, such as cheese (O'Mahony et al., 2005) and butter (Avramis et al., 2003). It has been shown that when manufacturing Emmental cheese, small MFG were more resistant to disruption and retained their native MFGM microstructure upon processing better than large MFG, resulting in a 2 to $5 \%$ higher cheese moisture content (Goudédranche et al., 2000; Michalski et al., 2003); this translates to an increase in 3 to $5 \%$ cheese yield. In addition, cheese made from small MFG exhibits improved elasticity and melting properties, as well as differences in sensory properties, such as texture and flavor (Avramis et al., 2003; Michalski et al., 2003; O'Mahony et al., 2005). This is in part due to the way MFG interact with the surrounding protein network (Michalski et al., 2002; Logan et al., 2013). Casein micelle size is the major determinant of rennet gel strength; however, we have shown that MFG of a certain size can enhance the rheological properties of the rennet gel structure, believed to be a result of an optimum alignment of MFG size to the casein micelle network pore size (Logan et al., 2013).

To date, the extent of natural variation in MFG size within a herd has been described to a limited extent. On-farm factors may be responsible for some of this variation, but inherent cow-to-cow variation may also exist. Couvreur and Hurtaud (2007) reported individual variability influenced MFG size more so than breed or stage of lactation. Furthermore, Mesilati-Stahy and Argov-Argaman (2014) reported differences in the triacylglycerol-to-polar lipid ratio, an indicator of MFG size, within gravity-separated fractions of milk sampled from 10 cows at varying stages of lactation. Possible links between cow diet and MFG size have also been 
reported by Avramis et al. (2003), who fed a fish meal protein supplement and found smaller MFG in the milk of those cows compared with the controls. A decrease in MFG size was also observed in milk from cows on a fresh pasture diet supplemented with cereal concentrate compared with a corn silage diet supplemented with soybean meal (Couvreur et al., 2007). Conversely, Graves et al. (2007) showed that supplementation with $4 \%$ soybean oil did not affect milk composition or MFG size. These differing reports on the effect of diet on MFG size suggest specific feeding strategies may effectively alter MFG distribution, such as feeding diets enriched in longer chain FA. This is likely due to the nature of FA incorporation during droplet formation and secretion, where longer chain FA with an even number of carbons originate from the cow diet or adipose tissue and shorter chain FA are synthesized de novo in the mammary gland (Wiking et al., 2004).

The current research aimed to measure and describe the extent of natural variation in MFG size within cows of a dairy herd. This was done with the view of defining the scope to select milk on the basis of MFG size and to optimize milk functionality for different purposes. In turn, this may assist the milk production and manufacturing sectors of the dairy industry to increase efficiency and maximize product quality.

\section{MATERIALS AND METHODS}

\section{Milk Samples}

The experiment used a total of 78 Holstein-Friesian cows of mixed age from the research herd maintained at the Department of Environment and Primary Industries at Ellinbank, Victoria, Australia (latitude $38^{\circ} 14^{\prime} \mathrm{S}$, longitude $145^{\circ} 56^{\prime} \mathrm{E}$ ). Due to the normal flux of cows in and out of a dairy herd, only 40 of these cows were common to every time point. Others dropped off or were added as the experiment proceeded. Generally, cows were calved in late winter or early spring of each year, and were milked twice daily through a common dairy parlor (at $\sim 0600$ and $1500 \mathrm{~h}$ ). Milk samples were collected in duplicate from cows at 3 time points over approximately 12 mo. These time points were autumn 2012 (T1; 60 cows sampled), spring 2012 (T2; 68 cows); and autumn 2013 (T3; 57 cows) so that sampling occurred twice in consecutive autumn periods and once in the spring in between them, near the beginning of the second lactation cycle. At each sampling point, milk yield was measured at consecutive afternoon and morning milkings using a DeLaval ALPRO milk metering system (DeLaval International AB, Tumba, Sweden). At the same time, in-line milk meters (DeLaval International $\mathrm{AB}$ ) were used to collect a representative sample (approximately 1\%) of the total milk of each cow sampled. Samples from the afternoon and morning milkings were stored separately at $4^{\circ} \mathrm{C}$ until delivery to the laboratory the following day.

At the time of the T1 and T3 samplings, all cows were managed as a single herd and grazed perennial ryegrass pasture supplemented with cracked wheat grain offered in the dairy and pasture silage in the paddock. Cows were enrolled in pre-existing nutrition experiments at the time of sampling for $\mathrm{T} 2$, where cows were receiving diets of either Lucerne cubes (no pasture; MultiCube Stockfeeds, Yarrawonga, Victoria, Australia) or a restricted allowance of perennial ryegrass pasture supplemented with a mixed ration containing wheat grain, canola meal, Lucerne hay, and maize grain. These experiments were conducted in accordance with the Australian Code of Practice for the Care and Use of Animals for Scientific Purposes (National Health and Medical Research Council, 2004). Approval to proceed was obtained from the Department of Environment and Primary Industries Agricultural Research and Extension Animal Ethics Committee.

\section{Proximate Analysis and $\mathrm{pH}$}

The concentration of fat, protein, and lactose in each milk sample was determined using a LactoScope FTIR 20 (Delta Instruments, Melbourne, Australia). Measurements of $\mathrm{pH}$ were made at $20^{\circ} \mathrm{C}$ using a PHM 93 Reference $\mathrm{pH}$ Meter (Radiometer, Copenhagen, Denmark) with a 2-point calibration ( $\mathrm{pH} 4$ and $\mathrm{pH} 7$ ). All samples were analyzed in duplicate.

\section{Examination of MFG Structure by Confocal Microscopy}

The method for selective staining of phospholipids located in the MFG membrane was adapted from that reported by Lopez et al. (2010). A fluorescent headgroup-labeled phospholipid analog 1,2-dioleoylsn-glycero-3-phosphoethanolamine-N-(lissamine rhodamine B sulfonyl) (Rh-DOPE; Avanti Polar Lipids Inc., Alabaster, AL) in $1 \mathrm{mg} / \mathrm{mL}$ of chloroform $(10 \mu \mathrm{L})$ was added to $0.5 \mathrm{~mL}$ of milk sample, which was mixed gently by inversion and incubated at room temperature in the dark for $60 \mathrm{~min}$. This phospholipid analog colocates with the natural phospholipids present within the milk sample. A $10-\mu \mathrm{L}$ stained milk sample was placed onto a glass slide, mixed thoroughly with an equal volume of $0.5 \%$ low-melting point agarose (in $10 \mathrm{~m} M$ phosphate buffer, $\mathrm{pH}$ 6.8), and covered with a coverslip. A Leica TCS SP5 confocal microscope (Leica Microsystems, Mannheim, Germany) was used to visualize the structure of the samples using a $543-\mathrm{nm} \mathrm{HeNe}$ 
laser to excite the fluorescent stain. Emitted light was collected between 570 and $600 \mathrm{~nm}$.

\section{Particle Size Analysis}

The MFG size distribution was determined using a Mastersizer (Malvern Instruments, Malvern, UK). The obscuration rate was maintained between 12 and $14 \%$, and samples were first treated with an EDTA and sodium hydroxide solution (35 mM, pH 7.0, 1:1 vol/vol) to dissociate casein micelles within the serum phase, ensuring the measured particle size distribution representing the MFG only. The refractive index for the MFG and water were taken as 1.46 and 1.33 , respectively. Absorbance was set at 0.001. The MFG size is obtained via a best fit using light scattering (Mie) theory and quoted as the volume-length mean diameter $d_{4,3}$ as follows: $d_{4,3}=\sum n_{i} d_{i}^{4} / \sum n_{i} d_{i}^{3}$, where $d_{i}=$ the square root of the upper $\times$ lower diameters or geometric mean and $n_{i}=$ the discrete number of particles. The measurement was carried out on duplicate milk samples.

\section{Phospholipid Analysis}

Milk was centrifuged at $2,500 \times g$ for $15 \mathrm{~min}$ at $4^{\circ} \mathrm{C}$ to obtain the cream. A subsample of cream (5.0 \pm $0.05 \mathrm{~g}$ ) was transferred to a Schott flask for total lipid extraction, based on the method of Bligh and Dyer (1959). Water was added $(2 \mathrm{~mL})$ and the flask was gently shaken to mix. A mixed solvent of methanol/ $\mathrm{CHCl}_{3}(2: 1 \mathrm{vol} / \mathrm{vol}, 30 \mathrm{~mL})$ was added, after which the flask was sealed and shaken at high speed for 30 min. This was followed by the addition of $\mathrm{CHCl}_{3}(10$ $\mathrm{mL})$ where the flask was again shaken (10 min). After this, water $(10 \mathrm{~mL})$ was added, and again the flask was shaken $(5 \mathrm{~min})$. The extract was filtered through filter paper (Whatman 541, Whatman International Ltd., Maidstone, UK) under a vacuum, and the white retentate was retained (extract 1). The filtrate was then transferred into a capped test tube and separate into 2 distinct phases by centrifuge at $900 \times g$ for 15 min at $5^{\circ} \mathrm{C}$, separated by a thin white layer. The top aqueous layer was removed and the white residue was collected into a flask, covered with $\mathrm{CHCl}_{3}$, and shaken (10 min) before being refrigerated overnight. After storage, the flask was again shaken $(10 \mathrm{~min})$ and the extract filtered under a vacuum. The filtrate (extract 2) was collected and combined with the bottom $\mathrm{CHCl}_{3}$ phase from the initial extraction. Anhydrous sodium sulfate was added to the combined $\mathrm{CHCl}_{3}$ extracts and the extracts filtered $[0.45 \mu \mathrm{m}$ of polytetrafluoroethylene (PTFE) syringe filter] into a clean vial. Analysis was based on that of Rombaut et al. (2005) using a semiprep nonpolar-HPLC guard column $(10 \mu \mathrm{m}, 33 \times 7$ $\mathrm{mm}$ i.d.) coupled with a matching analytical column (5 $\mu \mathrm{m}, 150 \times 4.6 \mathrm{~mm}$ i.d.; Grace Davidson Prevail Silica, Grace Davison Discovery Sciences, Bannockburn, IL). Extraction and analysis were conducted in duplicate.

\section{Statistical Analysis}

Results were expressed as the mean value \pm SD. One-way ANOVA was used to determine significance, with cow identity as the nonvariable factor and MFG size or polar lipid composition as the variable factor. Differences between means were considered significant at $P<0.05$.

\section{RESULTS AND DISCUSSION}

\section{Cow Age, DIM, and Milk Yield at Time of Sampling}

Milk from a total of 78 Holstein-Friesian cows, ranging between 2 and $10 \mathrm{yr}$ of age at the time of sampling, was collected in this experiment (Table 1). Most calved annually in late winter or early spring, with the exception of a small number of cows that were carried over (still milking) from the previous lactation cycle during the latter part of this experiment. The average DIM ranged between 192 and 341 at T1, 32 and 462 for T2, and 186 and 611 for T3. The stage of lactation of cows at any given time point can be determined by the DIM information, where a typical lactation length is 305 d in seasonally calving dairy systems in Australia. In general terms, the spring samples (T2) were collected near the beginning of one lactation cycle, whereas the autumn samples (T1 and T3) were collected near the end of the lactation. Milk yields were higher at T2 (ranging between 13.1 and 51.5 L) compared with both T1 (9.8-23.8 L) and T3 (2.8-23.1 L). Milk yields were higher at the beginning of lactation than in the mid and late phases because of the proliferation of secretory cells in the mammary epithelia after parturition as lactation gets underway (Holmes et al., 2003). Furthermore, milk yield can vary with the age of the cow, usually increasing rapidly over the first few years and reaching a plateau around their sixth lactation (Holmes et al., 2003). However, single-point analysis of cow age and milk yield did not show any correlation at any time point within this experiment.

\section{Size Distribution of MFG}

The mean MFG size for each individual cow milk sample across the 3 time points are plotted from smallest to largest in Figure 1, which shows the breadth of distribution for T1, T2, and T3. Marked natural variation in size was found within the range of cows examined 
Table 1. Number of cows in each age group at time of sampling for individual cows at autumn 2012 (T1), spring 2012 (T2), and autumn 2013 (T3)

\begin{tabular}{lccc}
\hline Item & $\mathrm{T} 1$ & $\mathrm{~T} 2$ & $\mathrm{~T} 3$ \\
\hline Age & & & \\
1 & 0 & 0 & 0 \\
2 & 7 & 8 & 8 \\
3 & 4 & 7 & 7 \\
4 & 5 & 8 & 6 \\
5 & 15 & 14 & 5 \\
6 & 6 & 8 & 12 \\
7 & 13 & 8 & 7 \\
8 & 9 & 6 & 8 \\
9 & 1 & 1 & 3 \\
10 & 0 & 5.8 & 6.1 \\
Average & 6.2 & 2.2 & 2.2 \\
SD & 1.9 & 68 & 57 \\
Cows (n) & 60 & & \\
\hline
\end{tabular}

for each time point. The smallest MFG sizes were 3.0, 2.5, and $2.9 \mu \mathrm{m}$ and the largest were 5.1, 5.7, and 5.1 $\mu \mathrm{m}$ for $\mathrm{T} 1, \mathrm{~T} 2$, and $\mathrm{T} 3$, respectively. Consistent natural cow-to-cow variation was observed at each time point, with an average MFG size across all samples of $3.9 \pm$ $0.4,3.9 \pm 0.5$, and $3.8 \pm 0.4 \mu \mathrm{m}$, respectively (Figure 2). A typical MFG size distribution in milk from one cow with a smaller mean MFG size and one with a larger mean MFG size is shown in Figure 3 using confocal imagery, where the encasing phospholipid trilayer of the MFGM is visible against the black background using Rh-DOPE as a fluorescent stain. Whereas both distributions contain globules of varying size, globules $>5 \mu \mathrm{m}$ in diameter are clearly more abundant in that of the larger MFG milk (Figure $3 \mathrm{~b}$ ) compared with the smaller MFG sample (Figure 3a).

Milk fat globule size is often cited as the volumeweighted mean (as in the current experiment) or as the surface-weighted mean. In either case, the reported value is an average of a broad distribution of globules within any given milk sample, as shown in Figure 3. It is likely this breadth of distribution will affect functionality, in addition to the shift in the mean MFG size value itself. Walstra (1969) proposed 3 subgroups of MFG within whole milk. The first group accounts for around $80 \%$ of the total number of globules and consists of very small MFG, $<1 \mu \mathrm{m}$ in size. The second group consists of the medium-sized globules and accounts for the greater majority of the lipid phase in terms of volume ( $\sim 94 \%)$. According to the model of Walstra (1969), the third group of MFG are those $<8 \mu \mathrm{m}$. Changes within this larger MFG portion have the greatest effect on the mean MFG value, particularly when the measured MFG size is based on volume. Others have shown that differences in MFG size are primarily a function of variation within this larger subpopulation, which tends

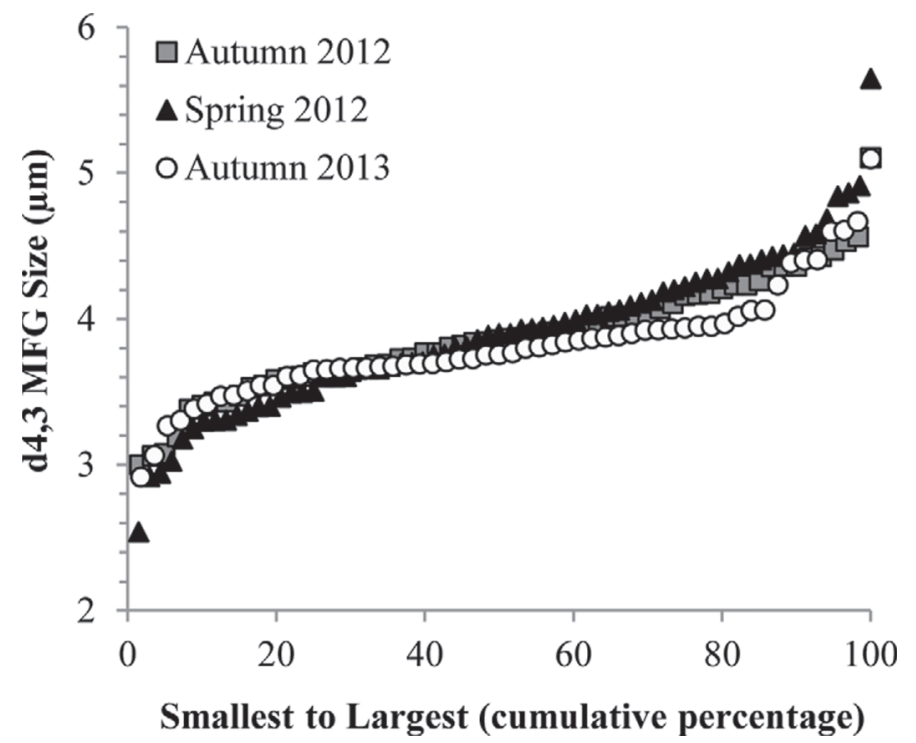

Figure 1. Milk fat globule (MFG) size cumulative percentage (smallest to largest) for individual samples at autumn 2012, spring 2012, and autumn 2013. $\mathrm{d}_{4,3}=$ the volume moment mean diameter.

to increase at the expense of the medium group in milks with larger MFG overall (Wiking et al., 2004).

The great majority of cows in the current experiment produced milk with a mean MFG size between 3 and $4 \mu \mathrm{m}$ in diameter (Figure 1). Despite this, a consistent number of cows at each extreme exhibited much smaller or much larger globules. The milk from these cows has the potential to be segregated to form discreet pools of milk with an overall small or larger MFG distribution.

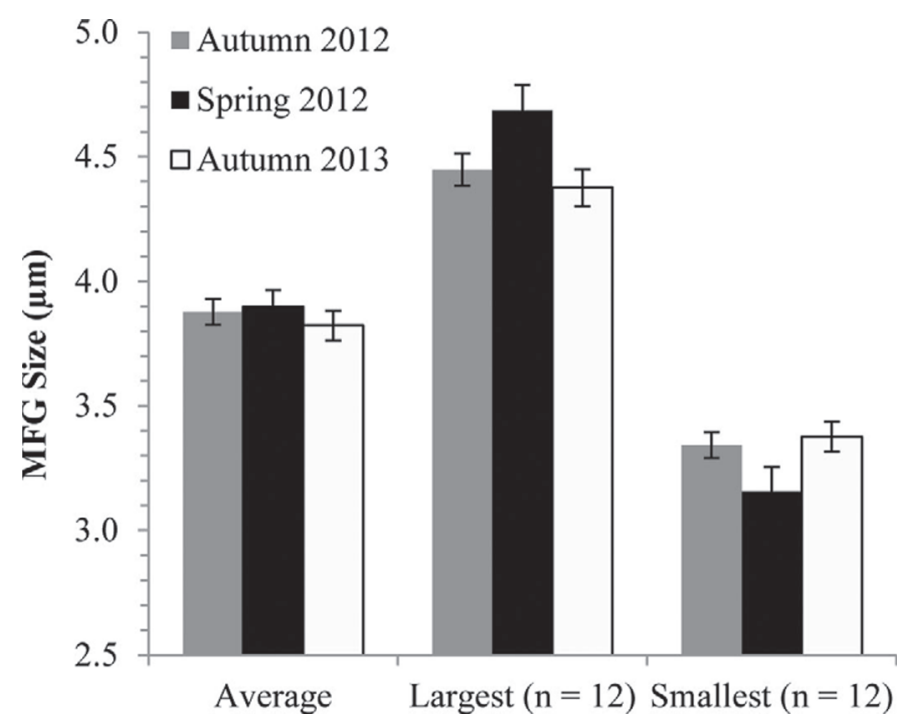

Figure 2. Average milk fat globule (MFG) size ( $\mu \mathrm{m})$ at autumn $2012(\mathrm{n}=60)$, spring $2012(\mathrm{n}=68)$, and autumn $2013(\mathrm{n}=57)$ for all samples, the 12 largest MFG-producing cows, and the 12 smallest MFG-producing cows. 

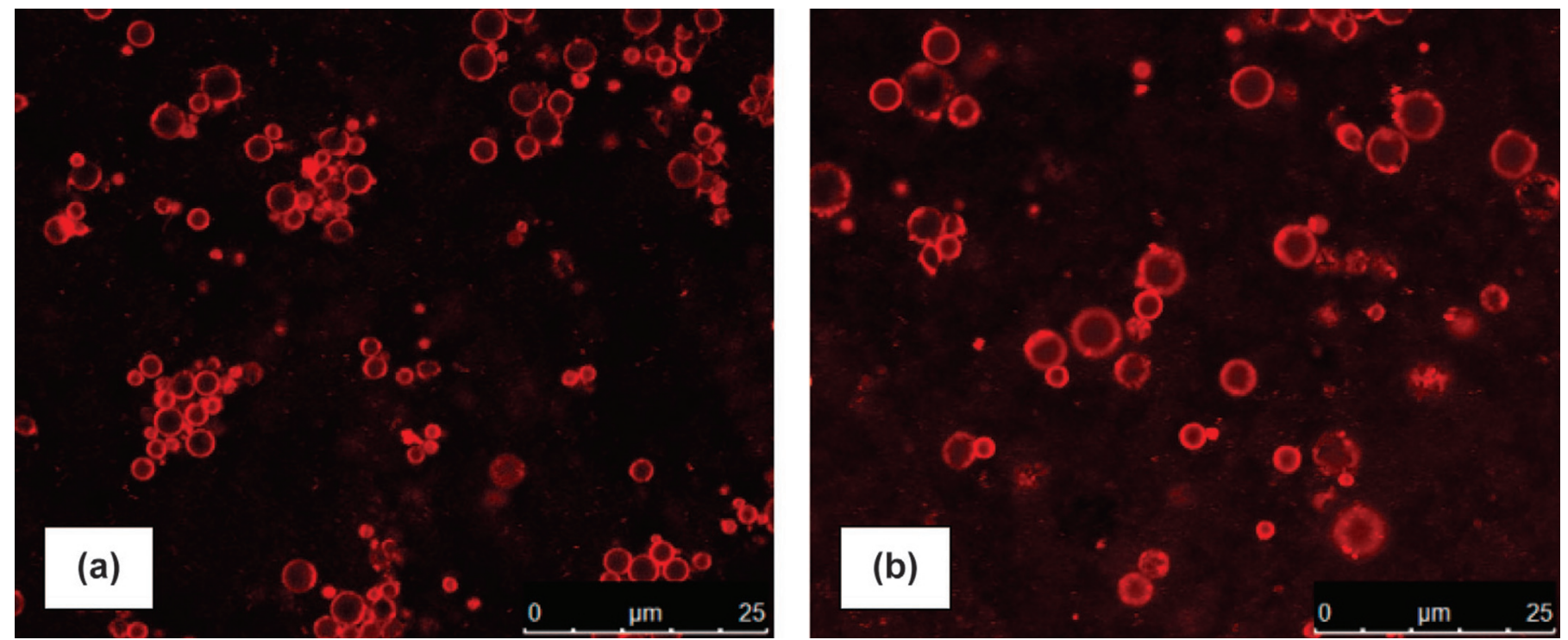

Figure 3. Confocal microscopy image $($ scale $=25 \mu \mathrm{m}$ ) stained with 1,2-dioleoyl-sn-glycero-3-phosphoethanolamine-N-(lissamine rhodamine B sulfonyl) (Rh-DOPE) of a typical milk with (a) small milk fat globule [MFG; volume moment mean diameter $\left.\left(\mathrm{d}_{4,3}\right)=2.9 \mu \mathrm{m}\right]$ and $(\mathrm{b})$ large MFG $\left(\mathrm{d}_{4,3}=4.7 \mu \mathrm{m}\right)$ sampled at autumn 2013. The fluorescent Rh-DOPE stain partitions within the MFG membrane encasing each globule, seen here in the image as spherical droplets. Color version available in the online PDF.

To demonstrate this potential, the 12 samples with the smallest mean MFG size and the 12 samples with the largest MFG size at each time point were examined separately as 2 discrete groups, and the average pooled MFG size for these groups is shown in Figure 2 compared with the average size of all samples combined. Based on an equal weighting for each of the 12 cows contributing to either the large or the small group, the overall MFG distribution of each was calculated. The small MFG group was smaller in MFG size (3.2 \pm 0.3 $\mu \mathrm{m})$ at T2 compared with milk from the same cows at $\mathrm{T} 1(3.3 \pm 0.2 \mu \mathrm{m})$ or T3 $(3.4 \pm 0.2 \mu \mathrm{m})$. Furthermore, the MFG size of the large group at T2 $(4.7 \pm 0.4 \mu \mathrm{m})$ was larger than either $\mathrm{T} 1(4.5 \pm 0.2 \mu \mathrm{m})$ or $\mathrm{T} 3(4.4 \pm$ $0.3 \mu \mathrm{m})$. This indicates greater variation in the breadth of size distribution from smallest to largest in early lactation. However, the average size of the small MFG pool was consistently below $3.4 \mu \mathrm{m}$, whereas the larger pooling had an average size over $4.4 \mu \mathrm{m}$. This degree of differentiation in size may be large enough to result in differing functionality during processing treatments, for example, response to renneting (Logan et al., 2013), cheese texture, color, and flavor (St-Gelais et al., 1997), and butter texture (Avramis et al., 2003).

Membranous proteins may play a role in the regulation of milk fat secretion and therefore MFG size. For example, links have been shown between the expression of butyrophilin and xanthine oxidase with milk secretion within rats (Vorbach et al., 2002; Ogg et al., 2004; Heid and Keenan, 2005; Robenek et al., 2006). Levels of milk secretion has also been linked to protein hormone expression, such as prolactin (Ollivier-Bousquet, 2002), and cow breed (Carroll et al., 2006; Graves et al., 2007). Differences in the FA associated with phospholipids may also affect membrane fluidity (e.g., FA with a higher melting point), hence the likelihood of globules to coalescence into a larger size (Bitman and Wood, 1990). Furthermore, Bitman and Wood (1990) found levels of polar lipids to decrease with stage of lactation. Differences in solid fat content of the lipid core due to varying levels of saturation may also affect the ability of MFG to fuse, thereby remaining small as it travels through the cytosol of the mammary gland from the point of formation within the endoplasmic reticulum (Timmen and Patton, 1988). It is also possible that factors responsible for seasonal variation in milk yield and composition as lactation progresses, such as physiological and endocrinological changes associated with stage of lactation, and nutritional changes associated with pasture availability and supplementary feed inputs, may contribute to the availability of MFGM and lipid precursors, and therefore MFG size (MesilatiStahy and Argov-Argaman, 2014).

\section{Polar Lipids}

Polar lipids (PL) are incorporated into the MFGM upon secretion, where the globule is enveloped by the apical plasma membrane of the secretary mammary cell. Analysis was conducted on a subgroup of 5 large- and 5 
small-MFG milks sampled at T3. The mean MFG size and PL content for each milk are shown in Table 2. The MFG size for the smaller group was $3.6 \mu \mathrm{m}$, whereas the MFG size for the larger group was $4.6 \mu \mathrm{m}$. The total PL content measured in the small-MFG milks was in the range of 0.47 to $0.68 \%$ (wt/wt) compared with 0.32 to $0.55 \%$ (wt/wt) in the larger MFG samples, indicating more PL was associated with the MFG of milks producing globules of smaller mean sizes compared with the larger MFG samples. Overall, PL content agrees with those reported in the literature by others (Rombaut et al., 2005), and the differences are consistent with the increased surface area provided by the smaller MFG, requiring more membranous material to completely cover the surface compared with larger globules.

The relative levels of individual PL characterized showed that phosphatidylethanolamine (PE) was the dominant PL, accounting for around $32 \%$ of total composition, followed by phosphatidylcholine (PC) and sphingomyelin (SM) at about 28 and $23 \%$, respectively (Table 2). The results are consistent with the findings of others in the literature (Fagan and Wijesundera, 2004; Rombaut et al., 2005; Lopez et al., 2008). No significant differences were observed between the different-sized globules, with the exception of PC, primarily located in the outer layer of the trilayer MFGM. The PC was present to a higher level in all smaller MFG milks $(29.8 \%)$ compared with those with larger globules (26.5\%), hence the ratio of PE to PC was higher in the larger MFG. Increased fusion rates have been measured in membranes containing $\mathrm{PE}$ compared with PC-containing membranes (Cohen et al., 1984), which could explain why some globules fuse within the mammary gland before secretion to form larger MFG, whereas others remain small. Another component located primarily in the outer layer is SM (Timmen and Patton, 1988). Higher levels of SM have been found in the lipid fraction of smaller MFG by others (Graves et al., 2007; Lopez et al., 2008); however, no significant differences $(P<0.05)$ in SM were found between the smaller and larger MFG samples in this work.

\section{Milk Fat Composition and Milk pH}

Figure 4 shows the correlations between MFG size and percentages of total fat content, protein, and lactose. No significant correlations were found, including MFG size with the concentration of fat in milk $\left(\mathrm{R}^{2}=\right.$ $0.33,0.17$, and 0.01 for $\mathrm{T} 1, \mathrm{~T} 2$, and $\mathrm{T} 3$, respectively). This is consistent with what has been reported in the literature for fat content (King, 1957; Walstra, 1969). More recently, Wiking et al. (2004) showed that fat content as a function of milk yield (diurnal fat production) was linked to MFG size and suggested that the synthesis of membranous material is limited when fat production increases. The results of the current experiment were also extrapolated and plotted as MFG size versus calculated fat production (e.g., percent fat in the milk as a function of milk yield), as shown in Figure 5. It is clear that such a relationship was not found $\left(\mathrm{R}^{2}=\right.$ $0.18,0.07$, and 0.00 for $\mathrm{T} 1, \mathrm{~T} 2$, and $\mathrm{T} 3$, respectively). Thus, it appears that limited synthesis of MFGM materials may not be a factor when fat production is increased. Evidence to suggest a correlation between total proteins, lactose, or milk pH with MFG size could not be found in the literature; therefore, the lack of correla-

Table 2. Milk fat globule (MFG) size, total polar lipids (PL; \%, wt/wt, of dried cream), and PL composition for selected small and large MFG milk sampled at T3 (autumn 2013)

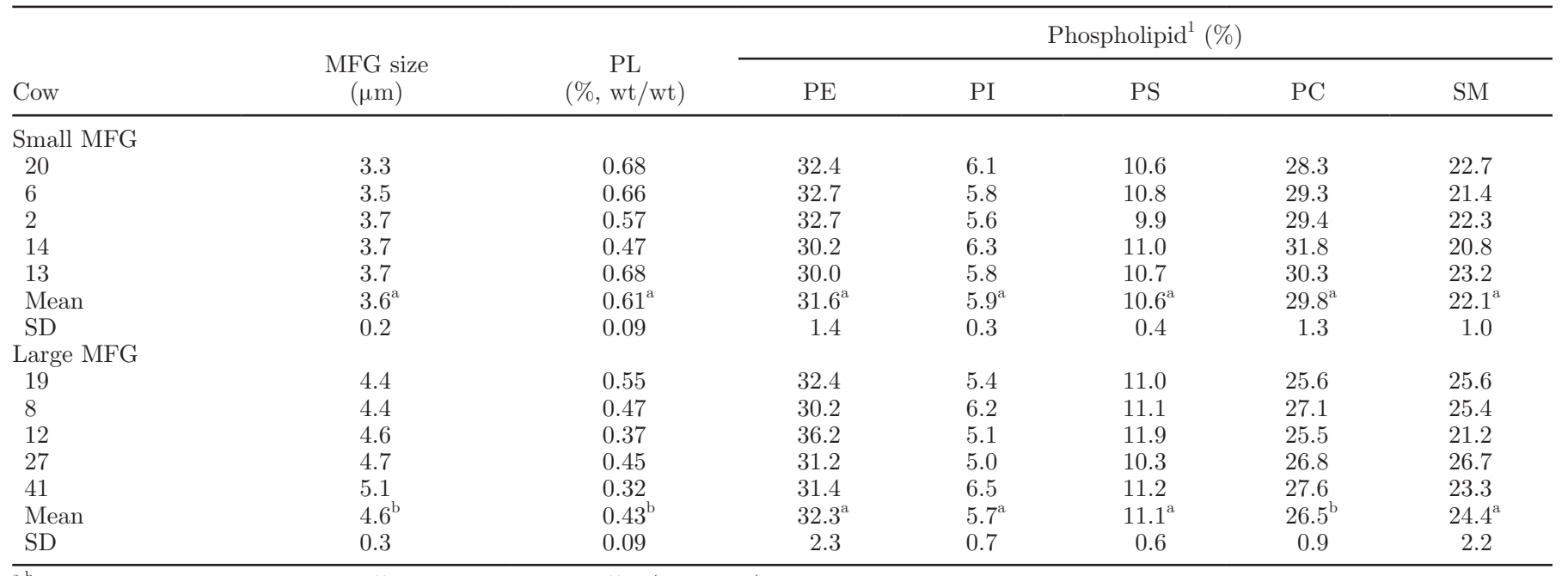

$\overline{\mathrm{a}, \mathrm{b}}$ Means within a column with different superscripts differ $(P<0.05)$.

${ }^{1} \mathrm{PE}=$ phosphatidylethanolamine; $\mathrm{PI}=$ phosphatidylinositol; PS = phosphatidylserine; $\mathrm{PC}=$ phosphatidylcholine; $\mathrm{SM}=$ sphingomyelin. 

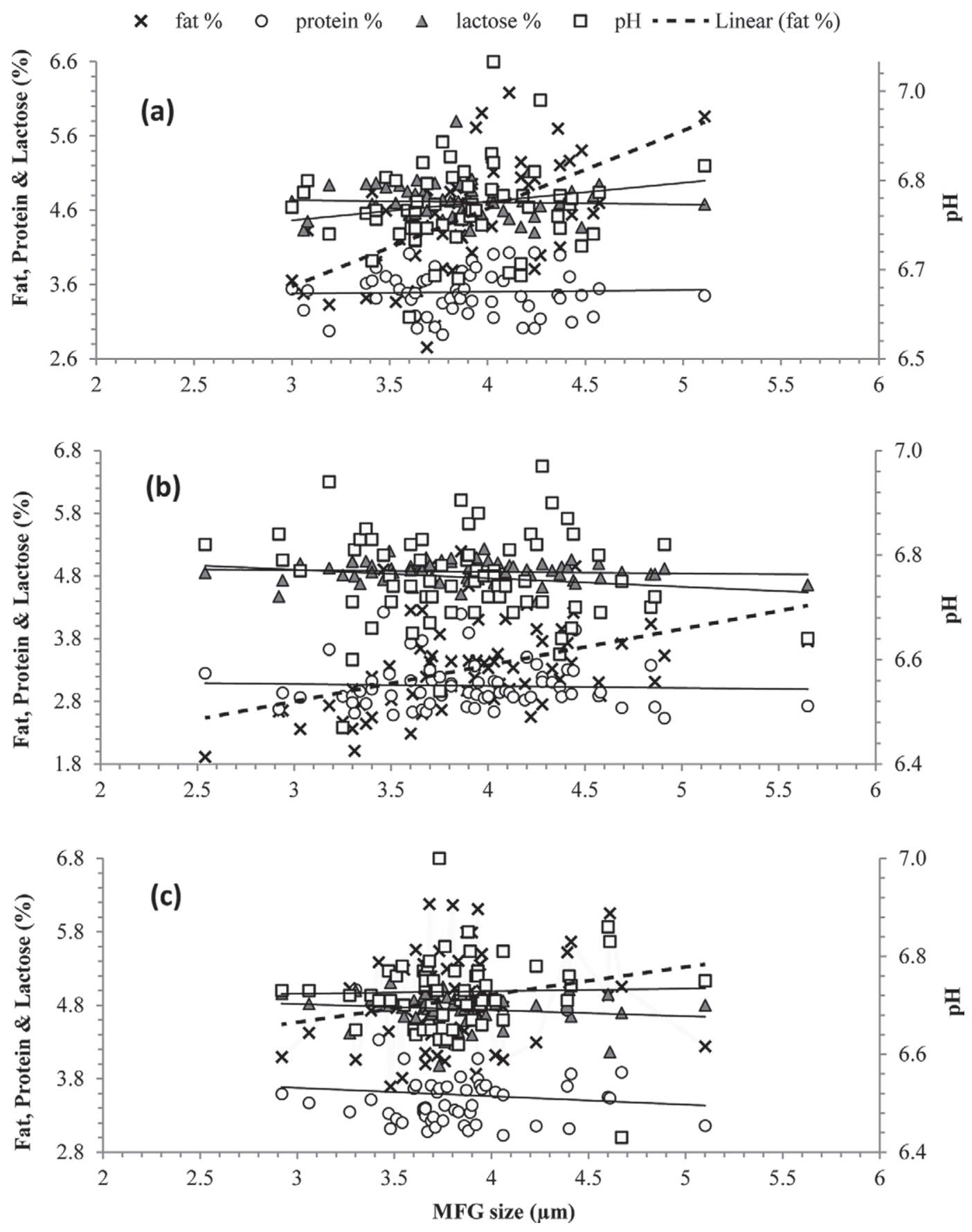

Figure 4. Average milk fat globule (MFG) size $(\mu \mathrm{m})$ versus fat (\%), protein (\%), lactose (\%; primary y-axis), and pH (secondary y-axis) at (a) autumn 2012, (b) spring 2012, and (c) autumn 2013.

tion documented herein is not surprising. Patton et al. (1977) suggested a possible link between serum phase composition and MFG secretion in a study looking at colchicine-induced suppression, where microtubule synthesis was inhibited. These tubules are necessary for serum phase secretion via a process of exocytosis, and an alternative mechanism for MFG secretion suggests it may occur via a similar pathway (Heid and Keenan, 2005). Regardless, whereas links might be present between protein and milk fat secretion, levels of protein in the milk serum phase do not appear to be associated with MFG size. 
Table 3. Change in mean milk fat globule (MFG) size and DIM for cows where significantly larger MFG were measured in spring (T2) compared with autumn of concurrent years (T1 and T3), and age of the cows at T3

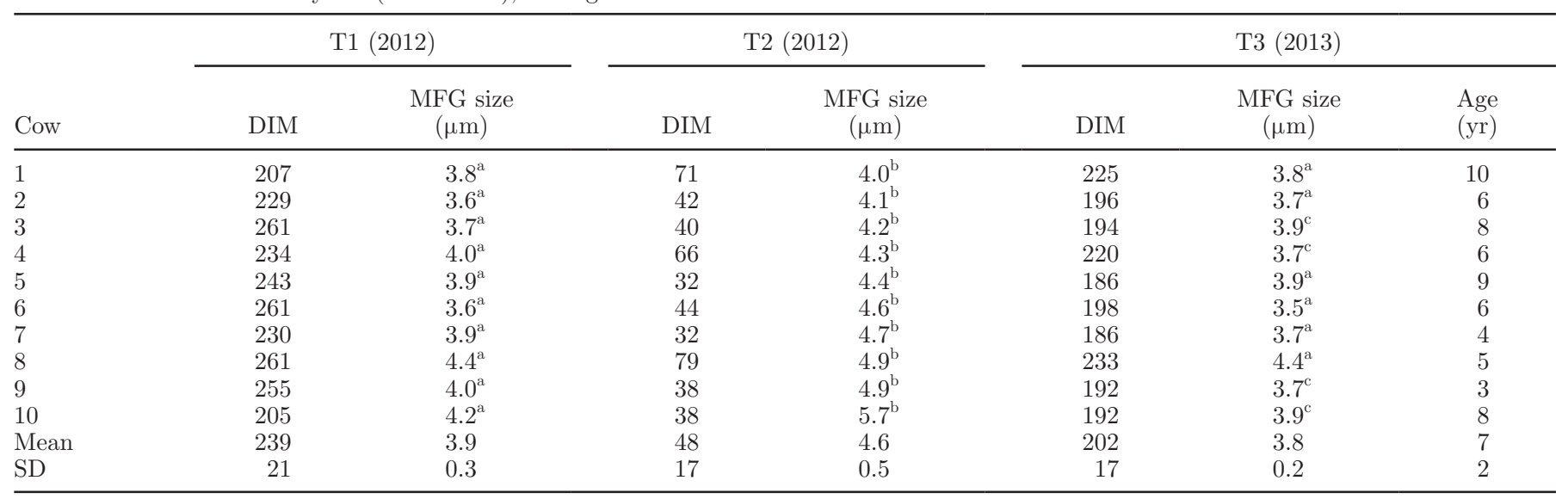

${ }^{\mathrm{a}-c}$ Means within a row with different superscripts differ $(P<0.05)$.

\section{Changes in MFG Size Through the Lactation Cycle and Seasonal Affects}

Forty individual cows were sampled at all of the 3 time points (T1, T2, and T3), and numbered 1 through to 40 for the purpose of this analysis (Tables $3-5$ ). The relative changes to MFG size through a typical lactation cycle and from year to year were examined to assess whether changes in MFG size occurred as lactation proceeded and if trends were consistent each year. Some of the cows sampled at T3 were enrolled in pre-existing nutrition experiments where their diets differed from those at T1 and T2. However, milk taken from cows immediately before and during the feeding experiments showed no effect on MFG size by the feed type used during the current experiment (data not shown).

Ten of these 40 cows exhibited significantly $(P<$ $0.05)$ larger MFG at T2 $(\mathrm{DIM}=48 \pm 17 \mathrm{~d})$ compared with T1 (autumn of the lactation cycle immediately prior, DIM $=239 \pm 22 \mathrm{~d}$ ) and T3 (autumn of the same lactation cycle, DIM $=202 \pm 17 \mathrm{~d}$ ). The average age within this group was $7 \mathrm{yr}$ old at the last samplingpoint (T3), ranging from 3 to $10 \mathrm{yr}$ of age (Table 3 ), and all cows in this group calved annually. Milk from these cows tended to have larger MFG (i.e., $>3.8 \mu \mathrm{m}$, with none below $3.5 \mu \mathrm{m}$ ).

A further 9 cows exhibited significantly smaller MFG at $\mathrm{T} 2(\mathrm{DIM}=162 \pm 160 \mathrm{~d})$ compared with T1 (DIM $=240 \pm 21 \mathrm{~d})$ and $\mathrm{T} 3(\mathrm{DIM}=316 \pm 160 \mathrm{~d})$. The average age of cows within this group was 5 yr old at T3, ranging between 3 and 8 yr of age (Table 4). Cow 19 produced larger MFG (i.e., $>3.8 \mu \mathrm{m}$ ) consistently throughout the experiment, whereas cow 11 produced smaller MFG at each time point $(\leq 3.0 \mu \mathrm{m})$. Unlike the previous example, the milks from these cows were not primarily large or small in size. Seven of these 9

Table 4. Change in mean milk fat globule (MFG) size and DIM for cows where significantly smaller MFG were measured in spring (T2) compared with autumn of concurrent years (T1 and T3), and age of the cows at T3

\begin{tabular}{|c|c|c|c|c|c|c|c|}
\hline Cow & \multicolumn{2}{|c|}{ T1 (2012) } & \multicolumn{2}{|c|}{ T2 (2012) } & \multicolumn{3}{|c|}{ T3 (2013) } \\
\hline 12 & 213 & $4.2^{\mathrm{a}}$ & 103 & $3.2^{\mathrm{b}}$ & 257 & $4.6^{\mathrm{c}}$ & 4 \\
\hline 13 & 242 & $3.6^{\mathrm{a}}$ & 72 & $3.3^{\mathrm{b}}$ & 226 & $3.7^{\mathrm{a}}$ & 4 \\
\hline 14 & 269 & $3.6^{\mathrm{a}}$ & 71 & $3.4^{\mathrm{b}}$ & 225 & $3.7^{\mathrm{a}}$ & 3 \\
\hline 18 & 260 & $4.6^{\mathrm{a}}$ & $(457)$ & $3.7^{\mathrm{b}}$ & (611) & $4.0^{c}$ & 3 \\
\hline 19 & 206 & $4.4^{\mathrm{a}}$ & 46 & $4.1^{\mathrm{b}}$ & 200 & $4.4^{\mathrm{a}}$ & 7 \\
\hline Mean & 240 & 3.87 & 162 & 3.40 & 316 & 3.90 & 5 \\
\hline SD & 21 & 0.48 & 160 & 0.41 & 160 & 0.50 & 2 \\
\hline
\end{tabular}

${ }^{\mathrm{a}-\mathrm{c}}$ Means within a row with different superscripts differ $(P<0.05)$.

${ }^{1}$ Parentheses indicate the cow is in extended lactation. 
Table 5. Change in mean milk fat globule (MFG) size and DIM for cows that exhibit with small or large MFG throughout the 3 time points (autumn 2012, spring 2012, and autumn 2013; T1, T2, and T3) and age of the cows at T3

\begin{tabular}{|c|c|c|c|c|c|c|c|}
\hline Cow & \multicolumn{2}{|c|}{$\mathrm{T} 1$} & \multicolumn{2}{|c|}{$\mathrm{T} 2$} & \multicolumn{3}{|c|}{ T3 } \\
\hline 21 & 210 & $3.9^{\mathrm{a}}$ & $(407)^{1}$ & $3.9^{\mathrm{a}}$ & $(561)$ & $3.9^{\mathrm{a}}$ & 7 \\
\hline 22 & 242 & $4.2^{\mathrm{a}}$ & 98 & $3.9^{\mathrm{b}}$ & 252 & $4.0^{\mathrm{b}}$ & 6 \\
\hline 23 & 266 & $3.9^{\mathrm{a}}$ & 104 & $4.0^{\mathrm{a}}$ & 258 & $3.9^{\mathrm{a}}$ & 6 \\
\hline 26 & 216 & $4.2^{\mathrm{a}}$ & 40 & $4.4^{\mathrm{a}}$ & 194 & $3.8^{\mathrm{b}}$ & 8 \\
\hline 27 & 259 & $4.4^{\mathrm{a}}$ & 75 & $4.8^{\mathrm{b}}$ & 229 & $4.7^{\mathrm{b}}$ & 5 \\
\hline Mean & 230 & 4.0 & 119 & 4.0 & 273 & 4.0 & 6 \\
\hline $\mathrm{SD}$ & 25 & 0.4 & 118 & 0.5 & 118 & 0.4 & 2 \\
\hline
\end{tabular}

$\overline{\mathrm{a}, \mathrm{b}}$ Means within a row with different superscripts differ $(P<0.05)$.

${ }^{1}$ Parentheses indicate the cow is in extended lactation.

cows were calved on an annual basis; however, 2 carried over from the lactation cycle before. These cows (cows 17 and 18) were in an extended lactation at the time of sampling, which suggests that the trend for smaller MFG in spring and larger MFG in autumn may not be linked with stage of lactation, because, as in the cows that had calved annually, they also exhibited smaller MFG size in spring and larger MFG in the autumn. It is possible that other factors that also change as lactation progresses, such as a changing availability of pasture and other feed inputs or photoperiod and climatic conditions, may also influence MFG size.

Seven cows exhibited consistently larger MFG (cows 21-27) and 1 cow (cow 20) exhibited consistently smaller MFG throughout T1 (DIM $=230 \pm 25 \mathrm{~d})$, T2 $(\mathrm{DIM}=119 \pm 118 \mathrm{~d})$ and $\mathrm{T} 3(\mathrm{DIM}=273 \pm 118 \mathrm{~d})$. The average age of these cows was 6 yr old at T3, ranging between 3 and 8 yr of age (Table 5). The remaining
13 cows exhibited no discernible trends in MFG size across $\mathrm{T} 1(\mathrm{DIM}=239 \pm 24 \mathrm{~d}), \mathrm{T} 2(\mathrm{DIM}=92 \pm 97 \mathrm{~d})$, or T3 $(\mathrm{DIM}=246 \pm 97 \mathrm{~d})$. The average age was $7 \mathrm{yr}$ old at T3, ranging between 3 and 9 yr of age (Table 6). The majority of cows in this group tended to produce average to large MFG.

\section{Consistency in MFG Size from Year to Year}

From the same group of 40 cows, 19 exhibited milk that was statistically similar with respect to MFG size at T1 and T3 (i.e., at the same time of year between 2 consecutive years). The other 21 cows had different sized globules from one year to the next. However, despite being statistically different, the largest difference was only $0.6 \mu \mathrm{m}$ (average of $0.4 \mu \mathrm{m}$ ); meaning that a large number of these cows remained consistent with respect to MFG size from year to year, though the mag-

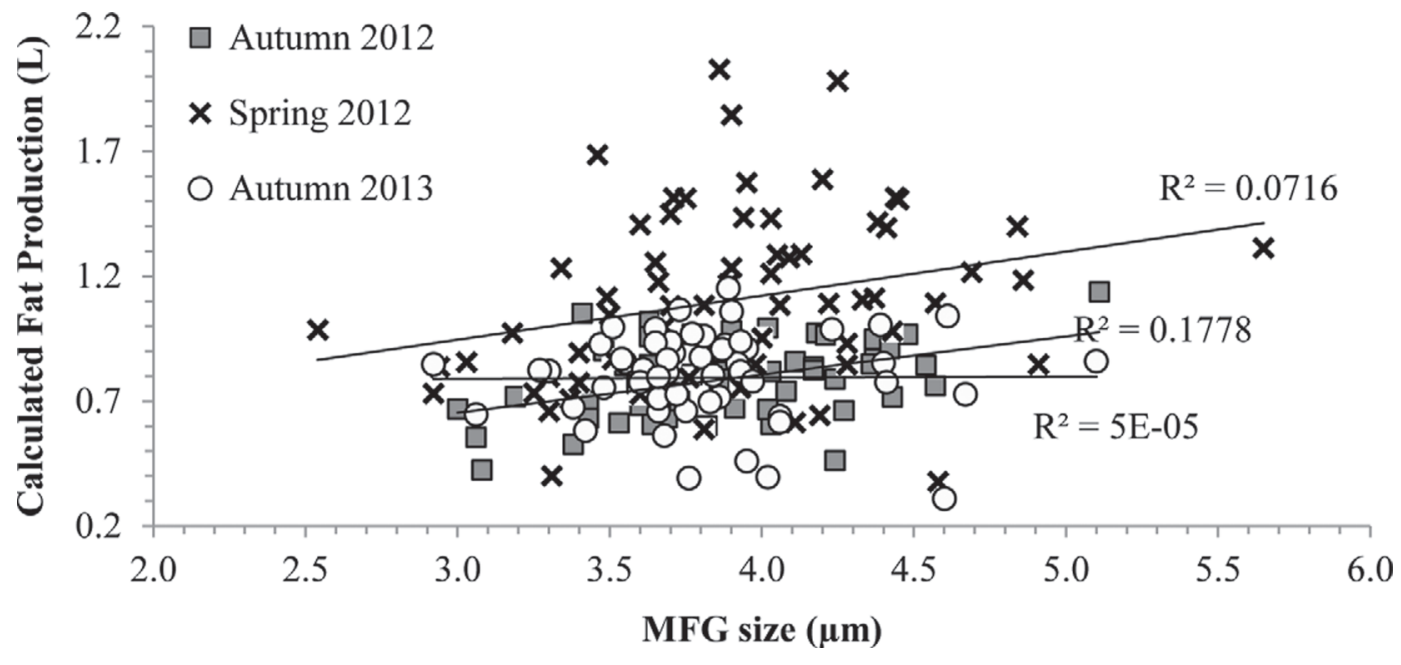

Figure 5. Average milk fat globule (MFG) size $(\mu \mathrm{m})$ versus calculated fat production (fat percentage in the milk as a function of milk yield). 
Table 6. Change in mean milk fat globule (MFG) size and DIM for cows where no trends in MFG in spring 2012 (T2) compared with autumn of concurrent years (2012 and 2013; T1 and T3) are observed as well as age of the cows at T3

\begin{tabular}{|c|c|c|c|c|c|c|c|}
\hline Cow & \multicolumn{2}{|c|}{$\mathrm{T} 1$} & \multicolumn{2}{|c|}{$\mathrm{T} 2$} & \multicolumn{3}{|c|}{ T3 } \\
\hline 29 & 224 & $3.9^{\mathrm{a}}$ & 92 & $3.5^{\mathrm{b}}$ & 246 & $3.7^{\mathrm{b}}$ & 7 \\
\hline 30 & 225 & $3.7^{\mathrm{a}}$ & 79 & $3.7^{\mathrm{a}}$ & 233 & $3.6^{\mathrm{a}}$ & 5 \\
\hline 31 & 257 & $3.9^{\mathrm{a}}$ & 35 & $3.7^{\mathrm{a}}$ & 189 & $4.2^{\mathrm{b}}$ & 7 \\
\hline 34 & 263 & $3.4^{\mathrm{a}}$ & 114 & $3.7^{\mathrm{b}}$ & 268 & $4.0^{\mathrm{c}}$ & 4 \\
\hline 35 & 253 & $3.6^{\mathrm{a}}$ & 106 & $3.7^{\mathrm{a}}$ & 260 & $3.7^{\mathrm{a}}$ & 6 \\
\hline 36 & 260 & $3.4^{\mathrm{a}}$ & 48 & $3.8^{\mathrm{b}}$ & 202 & $3.7^{\mathrm{b}}$ & 3 \\
\hline 37 & 210 & $3.7^{\mathrm{a}}$ & 69 & $3.9^{\mathrm{a}}$ & 223 & $3.5^{\mathrm{b}}$ & 6 \\
\hline 38 & 202 & $4.0^{\mathrm{a}}$ & 36 & $3.9^{\mathrm{a}}$ & 190 & $3.5^{\mathrm{b}}$ & 6 \\
\hline 39 & 202 & $3.6^{\text {ac }}$ & $(399)^{1}$ & $3.9^{\mathrm{b}}$ & (553) & $3.7^{\mathrm{bc}}$ & 7 \\
\hline 40 & 234 & $3.5^{\mathrm{a}}$ & 33 & $4.0^{\mathrm{b}}$ & 187 & $\begin{array}{l}3.1 \\
3.9^{\mathrm{b}}\end{array}$ & 9 \\
\hline
\end{tabular}

${ }^{\mathrm{a}-\mathrm{c}}$ Means within a row with different superscripts differ $(P<0.05)$.

${ }^{1}$ Parentheses indicate the cow is in extended lactation.

nitude may have varied slightly. Furthermore, no clear trend was evident across these samples. Eleven cows produced smaller MFG in 2013 compared with what they had produced the year earlier, whereas the average MFG size of the remaining 7 cows was slightly larger in 2013 compared with 2012. This indicates that MFG size is unlikely related to age of the cow. It appears no one factor or mechanism governs MFG size distribution. However, these results show that some cows within the herd produce either smaller or larger MFG. This presents the potential for milk to be selected and separately pooled to obtain bulk milk with a defined MFG size distribution.

We have shown that a natural cow-to-cow variation in MFG size exists within a single herd. This is the first time this has been shown within a dairy herd in Australia. However, no trend over the sampling time points was evident across all cows or samples. Despite this, a large proportion of cows produced milks with a consistent MFG size throughout the experiment, which covered 2 sequential lactation cycles; whereas smaller subsets of cows exhibited trends in MFG size as a typical lactation cycle proceeded (either becoming larger or smaller over time) and from year to year. Furthermore, trends observed in seasonally calved cows were similarly observed in cows (although limited in number) carried over from one lactation cycle to the next in extended lactation. These results suggest that variation in the MFG size observed between the sampling time points in this small proportion of cows are likely due to seasonal factors rather than a stage of lactation effect. Higher concentrations of polar lipids were determined in smaller compared with larger MFG due to the increased surface area of the smaller MFG. However, the relative proportions of individual polar components within the membrane did not differ with size, with the exception of PC, which was present to a higher extent within smaller MFG. No correlation was found between MFG size and milk fat proximate composition, including fat percentage and diurnal fat content or milk $\mathrm{pH}$.

\section{CONCLUSIONS}

Differences in MFG size can be found between cows within the herd studied, ranging from 2.5 to $5.7 \mu \mathrm{m}$. The fact that this difference is comparable to what can be achieved through mechanical fractionation and has been shown to result in differing functionality (Michalski et al., 2003) indicates it may be possible to obtain bulk milk of different-sized globules by separate pooling of milks from the largest and smallest MFG-producing cows. As this was a single-herd study, larger variations may be found in other herds or between different herds. Whether any advantage may be derived from naturally occurring differences in MFG size to produce dairy products with differentiated texture, improved yield, or improved processing, as shown by fractionated milks containing predominantly smaller or larger MFG, remains to be investigated.

\section{ACKNOWLEDGMENTS}

The authors acknowledge our colleagues from CSIRO Animal, Food and Health Sciences (Werribee, Victoria): Sean Moore for producing the confocal images, Zhiping Shen for phospholipids analysis, Michael Maz- 
zanetto and Jenny Favero for proximate analysis, and Allison Williams for assistance with the globule sizing measurement.

\section{REFERENCES}

Avramis, C. A., H. Wang, B. W. McBride, T. C. Wright, and A. R. Hill. 2003. Physical and processing properties of milk, butter, and Cheddar cheese from cows fed supplemental fish meal. J. Dairy Sci. 86:2568-2576.

Bitman, J., and D. L. Wood. 1990. Changes in milk fat phospholipids during lactation. J. Dairy Sci. 73:1208-1216.

Bligh, E. G., and W. J. Dyer. 1959. A rapid method of total lipid extraction and purification. Can. J. Biochem. Physiol. 37:911-917.

Carroll, S. M., E. J. DePeters, S. J. Taylor, M. Rosenberg, H. PerezMonti, and V. Capps. 2006. Milk composition of Holstein, Jersey, and Brown Swiss cows in response to increasing levels of dietary fat. Anim. Feed Sci. Technol. 131:451-473.

Cohen, F. S., M. H. Akabas, J. Zimmerberg, and A. Finkelstein. 1984 Parameters affecting the fusion of unilamellar phospholipid vesicles with planar bilayer membranes. J. Cell Biol. 98:1054-1062.

Couvreur, S., and C. Hurtaud. 2007. Globule milk fat: Secretion, composition, function and variation factors. Prod. Anim. 20:369-382.

Couvreur, S., C. Hurtaud, P. G. Marnet, P. Faverdin, and J. L. Peyraud. 2007. Composition of milk fat from cows selected for milk fat globule size and offered either fresh pasture or a corn silage-based diet. J. Dairy Sci. 90:392-403.

Fagan, P., and C. Wijesundera. 2004. Liquid chromatographic analysis of milk phospholipids with on-line pre-concentration. J. Chromatogr. A 1054:241-249.

Goudédranche, H., J. Fauquant, and J. L. Maubois. 2000. Fractionation of globular milk fat by membrane microfiltration. Lait 80:93-98

Graves, E. L. F., A. D. Beaulieu, and J. K. Drackley. 2007. Factors affecting the concentration of sphingomyelin in bovine milk. J. Dairy Sci. 90:706-715.

Heid, H. W., and T. W. Keenan. 2005. Intracellular origin and secretion of milk fat globules. Eur. J. Cell Biol. 84:245-258.

Holmes, C. W., I. M. Brookes, D. J. Garrick, D. D. S. Mackenzie, T. J. Parkinson, and G. F. Wilson. 2003. Milk Production from Pasture. Massey University, Palmerston North, New Zealand.

King, J. O. L. 1957. The association between the fat percentage of cow's milk and the size and number of the fat globules. J. Dairy Res. 24:198-200.

Logan, A., A. Pin, L. Day, R. Williams, M. Auldist, and M. A. Augustin. 2013. Selecting structures of key milk components for improved product functionality. Paper 34 in Proc. CIGR Section VII International Technical Symposium on Advanced Food Processing and Quality Management, Guangzhou, China.

Lopez, C., V. Briard-Bion, O. Menard, F. Rousseau, P. Pradel, and J. M. Besle. 2008. Phospholipid, sphingolipid, and fatty acid compositions of the milk fat globule membrane are modified by diet. J. Agric. Food Chem. 56:5226-5236.

Lopez, C., M. N. Madec, and R. Jimenez-Flores. 2010. Lipid rafts in the bovine milk fat globule membrane revealed by the lateral segregation of phospholipids and heterogeneous distribution of glycoproteins. Food Chem. 120:22-33.

Månsson, H. L. 2008. Fatty acids in bovine milk fat . Food Nutr. Res. 52. http://dx.doi.org/10.3402/fnr.v52i0.1821.
Mesilati-Stahy, R., and N. Argov-Argaman. 2014. The relationship between size and lipid composition of the bovine milk fat globule is modulated by lactation stage. Food Chem. 145:562-570.

Michalski, M. C., V. Briard, and P. Juaneda. 2005. CLA profile in native fat globules of different sizes selected from raw milk. Int. Dairy J. 15:1089-1094.

Michalski, M. C., V. Briard, and F. Michel. 2001. Optical parameters of milk fat globules for laser light scattering measurements. Lait 81:787-796.

Michalski, M. C., R. Cariou, F. Michel, and C. Garnier. 2002. Native vs. damaged milk fat globules: Membrane properties affect the viscoelasticity of milk gels. J. Dairy Sci. 85:2451-2461.

Michalski, M. C., J. Y. Gassi, M. H. Famelart, N. Leconte, B. Camier, F. Michel, and V. Briard. 2003. The size of native milk fat globules affects physico-chemical and sensory properties of Camembert cheese. Lait 83:131-143.

National Health and Medical Research Council. 2004. Australian Code of Scientific Purposes. 7th ed. Australian Government, Canberra, Australia.

O'Mahony, J. A., M. Auty, and P. McSweeney. 2005. The manufacture of miniature Cheddar-type cheeses from milks with different fat globule size distributions. J. Dairy Res. 72:338-348.

Ogg, S. L., A. K. Weldon, L. Dobbie, A. J. H. Smith, and I. H. Mather. 2004. Expression of butyrophilin (Btn1a1) in lactating mammary gland is essential for the regulated secretion of milk-lipid droplets. Proc. Natl. Acad. Sci. USA 101:10084-10089.

Ollivier-Bousquet, M. 2002. Milk lipid and protein traffic in mammary epithelial cells: Joint and independent pathways. Reprod. Nutr. Dev. 42:149-162.

Parodi, P. W. 2004. Milk fat in human nutrition. Aust. J. Dairy Technol. 59:3-59.

Patton, S., B. H. Stemberger, and C. M. Knudson. 1977. The supression of milk fat globule secretion by colchicine: an effect coupled to inhibition of exocytosis. Biochim. Biophys. Acta 499:404-410.

Robenek, H., O. Hofnagel, I. Buers, S. Lorkowski, M. Schnoor, M. J. Robenek, H. Heid, D. Troyer, and N. J. Severs. 2006. Butyrophilin controls milk fat globule secretion. Proc. Natl. Acad. Sci. USA 103:10385-10390.

Rombaut, R., J. V. Camp, and K. Dewettinck. 2005. Analysis of phospho-and sphingolipids in dairy products by a new HPLC method. J. Dairy Sci. 88:482-488.

Smoczynski, M., B. Staniewski, and K. Kielczewska. 2012. Composition and structure of the bovine milk fat globule membraneSome nutritional and technological implications. Food Rev. Int. $28: 188-202$.

St-Gelais, D., C. A. Passey, S. Hache, and P. Roy. 1997. Production of low-fat Cheddar cheese from low and high mineral retentate powders and different fractions of milkfat globules. Int. Dairy J. 7:733-741.

Timmen, H., and S. Patton. 1988. Milk-fat globules-Fatty-acid composition, size and in vivo regulation of fat liquidity. Lipids 23:685-689.

Vorbach, C., A. Scriven, and M. R. Capecchi. 2002. The housekeeping gene xanthine oxidoreductase is necessary for milk fat droplet enveloping and secretion: Gene sharing in the lactating mammary gland. Genes Dev. 16:3223-3235.

Walstra, P. 1969. Studies on milk fat dispersion II. The globule-size distribution of cow's milk. Neth. Milk Dairy J. 23:99-110.

Wiking, L., J. Stagsted, B. Lennart, and J. H. Nielsen. 2004. Milk fat globule size is affected by fat production in dairy cows. Int. Dairy J. 14:909-913. 